\title{
A CONVIVÊNCIA FAMILIAR E COMUNITÁRIA É DIREITO DA CRIANÇA E DO ADOLESCENTE E UMA REALIDADE A SER REPENSADA PELA ESCOLA
}

\author{
Maria Aparecida NerY*
}

RESUMO: O tema sobre a convivência familiar e comunitária como um direito de crianças e adolescentes, à primeira vista, se mostra bastante abstrato e ocupando ao mesmo tempo um lugarcomum. A sociedade aceita facilmente o fato de que toda criança tem direito a nascer e crescer em um lar saudável, protegido e seguro. Entretanto, muitas são as crianças que enfrentam situações de extrema vulnerabilidade pessoal e social, tendo que se afastar de suas famílias de origem para viver em situação de abrigamento, como medida protetiva. Este artigo tem como objetivo principal, a partir do que está preconizado no Plano Nacional de Promoção, Proteção e Defesa do Direito de Crianças e Adolescentes à Convivência Familiar e Comunitária e em leis anteriores (Constituição Federal Brasileira de 1988 e na Lei n. 8069/90 - Estatuto da Criança e do Adolescente), apresentar uma análise sobre os desafios e transformações que serão imprescindíveis para que esse direito seja efetivado, abordando os principais aspectos que envolvem as responsabilidades das políticas sociais brasileiras, com ênfase na educação pública.

Palavras-chave: Convivência familiar. Direito. Criança. Adolescente. Família. Medida protetiva. Políticas. Educação.

Doutoranda no Programa de Pós-Graduação em Educação Escolar da Faculdade de Ciências e Letras de Araraquara (UNESP) e professora da Pós-Graduação da Faculdade Anhanguera. E-mail: maria-nery@uol.com.br 
A convivência familiar e comunitária é direito da criança e do adolescente...

FAMILY AND COMMUNITY COEXISTENCE IS A RIGHT OF CHILDREN AND ADOLESCENTS AND A REALITY THAT SHOULD BE RETHOUGHT BY SCHOOL

ABSTRACT: At first sight, family and community coexistence as a legal right for children and adolescents seems quite abstract, although it occupies a common place. Society easily accepts that every child has the right to be born and raised within a healthy, protective and safe home. However, social and personal vulnerability force many children to leave their families and live in foster homes or shelters, as a protective measure. The main goal of this paper is to analyze the challenges and transformations needed in order to enforce children and adolescents' rights, in compliance with the National Plan for Social Devel opment, Protection and Defense of the Rights of Children and Adolescents to Family and Community Coexistence and other previous laws (1998 Brazilian Federal constitution and Law n. 8069/90 Children and Teenager's Statute), by approaching the main aspects involving the responsibilities of Brazilian social policies, with an emphasis on public education.

Key words: Family coexistence. Rights. Children. Adolescents. Family. Protective measures. Policies. Education.

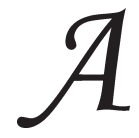

família vista como o espaço vital, em que toda criança tem direito a nascer e crescer em situação de proteção, afeto, segurança e cuidados, pode ser considerada um consenso na sociedade. As diferentes categorias profissionais - psicólogos, terapeutas, médicos, professores, advogados, entre outras - aceitam esta premissa sem muitos questionamentos, ainda que, para cada categoria, o termo família carregue suas especificidades e venha, ao longo dos anos, passando por significativas transformações. Tratar do tema família pode envolver vivências carregadas de representações, significados, opiniōes, juízos ou experiências as mais diversas. Podem ser incluídas as lembranças boas e ruins, afetos, desafetos, perdas e tantos outros componentes que, no conjunto, escrevem a história de vida de cada ser humano.

A família reflete, de muitas maneiras, as mudanças que ocorrem na sociedade e tem um papel, através dos seus atores, seja de pai, mãe, avô, filho, criança, adolescente, idoso, provedor(a), chefe de família etc. Cada um, nos seus limites, vai gerando transformações, se mudando e modificando até os papéis. Desde o movimento no espaço privado até 
a atuação no espaço público, no convívio com vizinhos, na comunidade, no trabalho vão se construindo as relações que estruturam a base de apoio no enfrentamento das dificuldades cotidianas.

À medida que a sociedade enfrenta seus desafios para superar condições adversas, a legislação brasileira vem também se avolumando para abarcar as mais complexas situações de violação de direitos humanos: direitos infanto-juvenis, direitos da pessoa idosa, direitos da mulher, enfim, de grupos sujeitos a maior vulnerabilidade. Este artigo faz um recorte, na área do direito da criança e do adolescente, tratando especificamente do direito à convivência familiar e comunitária e sua consequente relação com o contexto educacional.

A legislação brasileira preconiza que toda criança e adolescente tem direito a uma família, cujos vínculos devem ser protegidos pelo Estado e pela sociedade. Diante da vulnerabilidade social ou pessoal, da fragilização familiar, as estratégias de apoio ou de intervenção no atendimento à família devem priorizar ações que visem refazer os vínculos originais ou estimular a formação deles (se não existem), fortalecer esse núcleo, aliando apoio socioeconômico à elaboração de novas formas de interação e de acesso aos bens e serviços públicos.

Diante da complexidade que envolve o universo familiar, nossa reflexão, baseada em estudos compreensivos, sinaliza que, para as transformações necessárias para que o direito à convivência na família e na comunidade possa, de fato, se efetivar de forma ampliada será indispensável uma profunda integração das ações que perpassam as políticas públicas, em especial as políticas sociais. E, sobretudo, essa abordagem propõe uma análise mais cuidadosa sobre a responsabilidade daqueles que pensam e executam a política educacional.

A história social e cultural, no que se refere à atenção às crianças e adolescentes no país, mostra um passado de humilhação e precariedade. Os registros sobre a institucionalização de crianças no Brasil apontam, na década de 1730, para a abertura de casas que ficaram conhecidas como a "Roda dos Expostos". Nelas eram instaladas roletas, uma espécie de cilindro rotativo, que permitiam colocar as crianças do lado de fora e girar no sentido interno, preservando-se o anonimato daqueles que as levavam até esses lugares. Conforme pesquisas de Rizzini (2000), embora os registros sobre este sistema sejam controvertidos, apontam que, além de acolher crianças filhas de mães solteiras e mães 
A convivência familiar e comunitária é direito da criança e do adolescente...

muito pobres, serviam às famílias ricas para camuflar nascimentos fora do casamento e também àquelas nascidas de relaçôes incestuosas.

Centenas de anos se passaram e, ainda hoje, muitas são as famílias que vivem em situações de dificuldades para criar e educar seus filhos. Muitos são os meninos e meninas vivendo em condições de abrigamento institucional, apesar de todas as modificaçóes e progressos demonstrados nas práticas e preconizados pela legislação.

Para se tratar do tema convivência familiar e comunitária em nosso país, é preciso também considerar a influência de toda a normativa internacional, ratificada em caráter especial pelo Brasil, ${ }^{1}$ e a estabelecida por meio de resoluções da Assembléia Geral das Nações Unidas. Há que se reconhecer o quanto a legislação brasileira é abrangente na garantia dos direitos de crianças e adolescentes e sua ênfase na visão multidisciplinar e intersetorial para dar respostas à complexidade da situação.

O mais recente documento legal, aprovado em dezembro de 2006 - o Plano Nacional de Proteção, Defesa e Garantia do Direito da Criança e do Adolescente à Convivência Familiar e Comunitária -, complementa e regulamenta a garantia de direitos já enunciados pela Constituição Federal de 1988, pelo Estatuto da Criança e do Adolescente (ECA), em 1990 (Lei Federal n. 8.069), e pela Lei Orgânica da Assistência Social, de 1993. Tendo essa legislação como principal suporte, abordando o direito à convivência familiar e comunitária, buscaremos refletir sobre a responsabilidade das políticas sociais, em especial naquilo que irá contemplar o atendimento às famílias em situação de maior vulnerabilidade social e pessoal.

Sobre a dimensão da institucionalização de crianças e adolescentes no Brasil, é preciso recordar que a pesquisa realizada pelo Instituto de Pesquisa Econômica Aplicada (IPEA), em 2003, aponta um número de vinte mil crianças abrigadas em 589 instituições de abrigo no país. ${ }^{2}$ É importante considerar que os números referentes às medidas protetivas estão sempre demandando atualização, visto que a entrada e saída de crianças nos abrigos também ocorrem diariamente.

Inserida na "medida protetiva", de acordo com o estabelecido pelo ECA (Título II), a criança ou adolescente ficará em situação de abrigamento, podendo ser acolhida por uma instituição, sob guarda de pessoa da própria família (avós, tios etc.) ou de outra família, dependendo dos programas em funcionamento no município. Isto deve ser 
em caráter de provisoriedade, podendo a criança ou adolescente retornar à família de origem, assim que for superada a situação que gerou o afastamento. Decorrido algum tempo do abrigamento e após estudo aprofundado pela equipe técnica do Judiciário, poderá ser decretadas, pelo juiz da Vara da Infância, a suspensão do poder familiar ou a destituição dos pais e de seus deveres em relação aos filhos. Ocorrendo a suspensão do poder familiar, a criança ou adolescente deverá permanecer no abrigo, aguardando a possibilidade de adoção por uma nova família.

\section{O Plano Nacional de Proteção, Defesa e Garantia do Direito da} Criança e do Adolescente à Convivência Familiar e Comunitária

O documento aprovado pelos dois conselhos de políticas públicas, Conselho Nacional de Direitos da Criança e do Adolescente (CONANDA) e Conselho Nacional de Assistência Social (CNAS), tem 160 páginas e está organizado em capítulos que apresentam o histórico, o marco legal, o marco conceitual e o marco situacional, contextualizando todo o processo. A seguir, estabelece as diretrizes do Plano, seus objetivos, os resultados programáticos, as propostas de implementação, monitoramento e avaliação, finalizando pelo Plano de Ação.

A elaboração desse Plano exigiu o envolvimento de representantes institucionais e recursos de vários poderes, entre eles, das entidades civis de atendimento à criança e ao adolescente, do Fórum Colegiado de Conselheiros Tutelares, do Ministério do Desenvolvimento Social, do Ministério da Justiça, da Secretaria Especial dos Direitos Humanos, do Fundo das Nações Unidas para Infância (UNICEF), da Comissão de Direitos Humanos da Câmara dos Deputados, do Conselho Nacional de Direitos da Pessoa Portadora de Deficiência (CONADE), além dos dois outros já mencionados (CNAS e CONANDA). ${ }^{3}$

Sob a égide dos princípios legais, listaremos a seguir alguns documentos básicos que dão sustentação ao Plano, partindo da Constituição Federal (1988), que estabelece:

Artigo 226 - A família, a base da sociedade, tem especial proteção do Estado.

Está explicitado no inciso $8^{\circ}$ : O Estado assegurará a assistência à família na pessoa de cada um dos que a integram, criando mecanismos para coibir a violência no âmbito de suas relações. 
A convivência familiar e comunitária é direito da criança e do adolescente...

Artigo 227 - É dever da família, da sociedade e do Estado assegurar à criança e ao adolescente, com absoluta prioridade, o direito à vida, à saúde, à alimentação, à educação, ao lazer, à profissionalização, à cultura, à dignidade, ao respeito, à liberdade e à convivência familiar e comunitária, além de colocá-los a salvo de toda forma de negligencia, discriminação, exploração, violência, crueldade e opressão.

$\mathrm{O}$ artigo 227, tratando ainda do dever da família, da sociedade e do Estado, explicita, no parágrafo $6^{\circ}$ : "Os filhos, havidos ou não da relação do casamento, ou por adoção, terão os mesmos direitos e qualificações, proibidas quaisquer designações discriminatórias relativas à filiação". E, no artigo 229, estabelece que "Os pais têm o dever de assistir, criar e educar os filhos menores (...)".

A legislação brasileira nesse segmento, segundo autores como Silva Pereira (1996) e Costa (1998), entre outros, contou com a inspiração de movimentos internacionais que foram determinantes, como a Declaração de Genebra (1924), a Declaração sobre os Direitos da Criança (1924/1959), a Declaração Universal dos Direitos Humanos (1948), a Declaração Americana dos Direitos e Deveres do Homem (1948), o Pacto de São José da Costa Rica (1969), as Diretrizes de Riad para a prevenção da delinquência juvenil e as Regras Mínimas das Naçôes Unidas para proteção de jovens privados de liberdade, ambos os documentos aprovados, em 1990, pela Assembléia Geral da ONU (Costa, 1998). Do ponto de vista da garantia de direitos, esses avanços se consolidam com a promulgação da Lei Federal n. 8.069/90, em 13 de julho de 1990, em consonância com as diretrizes aprovadas na Convenção Internacional dos Direitos da Criança e do Adolescente, em 20 de novembro de 1989, fazendo com que o país adotasse uma nova doutrina em relação à formulação e implementação das políticas públicas dirigidas à infância e à adolescência. Anterior à elaboração do Estatuto, as políticas jurídicas e socioeducativas tinham como pano de fundo a doutrina da situação irregular, na qual o Código de Menores era baseado.

A diferença de concepção é muito clara, segundo a afirmação de Costa (1998): enquanto o Código de Menores vê a criança e o adolescente como objeto, aplicando-lhes um conjunto de regras coercitivo-punitivas, em geral para os "menores em situação irregular", o que equivalia a considerar criança pobre, abandonada ou "delinquente", o Estatuto propõe atender a todas as crianças e adolescentes, respeitando-os como 
"sujeitos de direitos", dentro da chamada Doutrina da Proteção Integral. Essa nova legislação traz em seu bojo concepções significativas, quando estabelece que:

- todas as crianças têm direitos iguais, sem discriminaçóes;

- as crianças e adolescentes são responsabilidades da família, do Estado e da sociedade;

- as crianças e adolescentes devem ser considerados como prioridade absoluta no conjunto das políticas públicas;

- crianças e adolescentes devem ser tratados como "pessoas em condição peculiar de desenvolvimento".

Além de enfatizar o que a Constituição Federal de 1988 já havia definido no artigo 227, sobre o direito à convivência familiar e comunitária, o ECA, em seu artigo $4^{\circ}$, vem referendar o enunciado. Para facilitar a compreensão do leitor, este artigo será reproduzido na íntegra:

Art. $4^{\circ}$ - É dever da família, da comunidade, da sociedade em geral e do Poder Público assegurar, com absoluta prioridade, a efetivação dos direitos referentes à vida, à saúde, à alimentação, à educação, ao esporte, ao lazer, à profissionalização, à cultura, à dignidade, ao respeito, à liberdade e à convivência familiar e comunitária. (ECA, 1990)

Complementado pelos artigos 19 e 20, que estabelecem:

Art. 19 - Toda criança ou adolescente tem direito a ser criado e educado no seio da sua família e, excepcionalmente, em família substituta, assegurada a convivência familiar e comunitária (...).

Art. 20 - Os filhos havidos ou não da relação do casamento, ou por adoção, terão os mesmos direitos e qualificaçôes, proibidas quaisquer designaçōes discriminatórias relativas à filiação. (Idem, ibid.)

Para as situações de acolhimento institucional (abrigamento em casas-lares), a legislação estabelece o caráter de provisoriedade e de excepcionalidade. Ou seja, essa medida deverá ser adotada como última alternativa, depois de esgotadas todas as possibilidades.

No capítulo II do Estatuto, que trata do trabalho das Entidades de Atendimento, artigos 90 a 94 e no artigo 100, há clareza sobre as responsabilidades das organizaçôes e de seus dirigentes, no sentido de 
A convivência familiar e comunitária é direito da criança e do adolescente...

assegurar que sejam respeitados todos os direitos da criança e, sobretudo, da tarefa de desenvolver ações para a preservação dos vínculos familiares.

Ressalta-se a condição de incompletude institucional prevista para os serviços de acolhimento, ou seja, a organização não deve funcionar no modelo de "instituição total", ofertando todos os serviços em seu interior e, ao mesmo tempo, mantendo as crianças e adolescentes enclausurados. Como titulares de direitos devem permanecer integrados na rede de atendimento de saúde, cultura, educação, nos serviços da comunidade propiciados pelas demais organizações, envolvendo projetos de dança, teatro, esporte, lazer, profissionalização e outros que venham frequentando ou tenham necessidade. Destaca-se também (artigo 92) que sejam envidados todos os esforços para manter juntos os grupos de irmãos.

No que tange ao marco conceitual, é indispensável chamar a atenção para a questão da compreensão do termo família - o sentido, o significado, o entendimento da forma mais ampla. A Constituição Federal (1988), em seu artigo 226, parágrafo 40, explicita: "Entendese, também, como entidade familiar a comunidade formada por qualquer dos pais ou descendentes". Na mesma esteira, o ECA, no artigo 25, assim preconiza: "Entende-se por família natural a comunidade formada pelos pais ou qualquer deles e seus descendentes".

Dessa forma, independente do tipo de arranjo familiar, não importando se a família seja classificada como "nuclear, monoparental ou reconstituída", a ênfase está na existência de vínculos de filiação de origem natural ou adotiva, conferindo-lhe igualdade de direitos. Este formato, seguramente, propóe superar o modelo "ideal de família", que tem ênfase na "estrutura" para enfatizar a sua capacidade de exercer a função de proteção, de socialização e de cuidados das suas crianças e adolescentes, considerando também outras possibilidades de arranjos.

Desta realidade começa a emergir um modelo de família que se estende para além da unidade casal (papai, mamãe e criança), da unidade pais e filhos, vivendo ou não no mesmo domicílio, na concepção tradicional. Este novo modelo considera uma família ampliada, a "família extensa". Em suma, propõe a compreensão para além do espaço físico, para um modelo que reconhece e valoriza a rede de vínculos. É preciso compreender a diversidade de organizações familiares, a 
complexidade e riqueza dos vínculos familiares e comunitários. Mais do que isso, é preciso superar o modelo estático e reconhecer um modelo dinâmico, ainda que convivam, concomitantemente, os diferentes modelos e que o tradicional carregue seu valor intrínseco. Não se trata aqui de valorizar um novo modelo familiar e desconstruir o anterior.

É importante também considerar que, além das obrigações de caráter legal, de natureza jurídica, existem aquelas de caráter simbólico e afetivo, construídas pela presença, amizade, convivência e/ou apadrinhamento. Podem ser profundamente fortes, espontâneas e, por vezes, mais significativas que algumas relaçóes de parentescos. Ainda que estas relações espontâneas tenham esse grau de relevância, elas também não são suficientes, do ponto de vista estrito da lei, para a garantia de direitos. Elas devem ser preservadas, mas serão necessários os trâmites que regularizam toda a complexidade jurídica do processo e de responsabilização das funções, seja de pai, mãe ou guardião.

Outro aspecto que requer observação cuidadosa, ainda reconhecendo a família como lugar de proteção, segurança e cuidado, é que ela também pode tornar-se o foco do conflito, revelando-se como o espaço silencioso da violação de direitos da criança e do adolescente. Violência esta que perpassa as diferentes faces: a violência psíquica, simbólica, a negligência, os maus tratos, ou a violência física, agressão, exploração e a violência sexual, o estupro, a drogadição, podendo desencadear sequelas gravíssimas e mesmo a morte. Algumas delas levam ou empurram também para fora dos lares, para o espaço das ruas, para o plano da violência urbana, seja como causa ou como consequência.

É muito importante perceber que o artigo 23 do Estatuto preconiza que a pobreza material, a falta/carência de recursos materiais não constitui motivo suficiente para a perda ou suspensão do poder familiar. Não existindo outros motivos que levem o Poder Judiciário a afastar a criança ou adolescente da sua família de origem, compete então exigir que essa família seja obrigatoriamente inserida em programas oficiais de auxílio. Essa atribuição é da responsabilidade dos gestores das políticas sociais no município e pode ser requerida pelo Ministério Público, caso não esteja sendo cumprida.

Os artigos 101 e 129 do Estatuto, tratando das medidas específicas de proteção, referindo-se também aos pais ou responsável legais, 
A convivência familiar e comunitária é direito da criança e do adolescente...

recomendam ações que proporcionem a inclusão da família em programas de auxílio e proteção, visando superar as dificuldades e restaurar os direitos. Esses programas não podem prescindir de um plano de trabalho construído com a família, de forma participativa e com compromissos mútuos. Tal plano deverá abarcar dimensões que ofereçam respostas para a superação de vulnerabilidades que envolvam:

- a condição de miserabilidade, incluindo a forma de morar (habitabilidade), a segurança alimentar, a geração de trabalho e renda.

- a forma de relacionar-se e de vivenciar os diferentes papéis e responsabilidades de pai, de mãe, de filho e assim por diante, visando superar conflitos e romper o ciclo de violência, muitas vezes transgeracional.

- integração sociocomunitária da família, acesso aos serviços públicos e/ou à rede de apoio até a orientação jurídica, se necessária.

O artigo 130 do ECA estabelece um dos aspectos que tem sido de difícil aplicação, ao tratar de casos de violência praticada por familiar ou responsável, com o qual a criança ou o adolescente convive sob o mesmo teto, prevendo o afastamento do agressor da moradia comum. Situações assim são muitas vezes camufladas pelas próprias mães, quando se tratam de companheiros, padrastos ou mesmo o pai biológico, em função de serem considerados os principais ou únicos provedores do sustento de toda a família, e/ou também por dependência afetiva e até por medo.

É importante considerar que a decisão de afastamento da criança ou adolescente da família, quando encaminhada pelo Conselho Tutelar, mesmo que seja temporário, e ainda que efetuada em situação de emergência, deverá ser comunicada ao Ministério Público e à autoridade judiciária. Para a tomada de decisão sobre o afastamento dessa criança ou adolescente, o juiz da Vara da Infância deverá contar com o apoio da equipe técnica, através de trabalhos e relatórios com diagnóstico detalhado de cada caso. Esse trabalho será desenvolvido por equipe interdisciplinar qualificada para lidar com a problemática. Para elaboração desse estudo, é recomendado que a equipe ouça inclusive a criança ou adolescente, usando metodologia adequada ao seu grau de desenvolvimento e capacidades. 
O serviço de acolhimento pode ser então oferecido pelas instituiçōes (casas-lares, repúblicas para adolescentes etc.) e pelas famílias acolhedoras, família-guardiã, família cuidadora ou família solidária. Deve ser garantido que a criança receba os cuidados necessários e as condições favoráveis para o desenvolvimento saudável; além disso, devem ser também investidos esforços e recursos, no sentido de viabilizar a reintegração à família de origem, dentro do menor tempo possível.

$\mathrm{O}$ ECA estabelece ainda uma série de exigências para o acolhimento institucional, previstas nos artigos 92 , complementados pelos artigos 90, 91, 93 e 94. Já comentamos vários desses aspectos nos itens anteriores. E o artigo 101 também trata das medidas específicas de proteção, incluindo, por exemplo, a frequência obrigatória à escola, tratamento médico, psicológico ou psiquiátrico, quando necessário, até a inclusão de familiares em tratamento para superar a dependência química, das drogas e do álcool.

Relativo ao acolhimento em famílias-guardiãs, acolhedoras ou solidárias, é necessário observar que o encaminhamento da criança para essa família deve ser feito também mediante estudo elaborado por equipe técnica, detalhando o perfil da criança e analisando as condições de adequação ao grupo familiar. Será feito um termo de guarda provisória expedido pela autoridade judiciária.

E, para finalizar, no que se refere à questão da adoção, é também uma medida de excepcionalidade, tem caráter irrevogável e vai atribuir a condição de filho ao adotado, com os mesmos direitos e deveres, conforme estabelece o artigo 41 (ECA). Essa medida deve ser tomada sempre orientada pelo interesse superior da criança e com a perspectiva de lhe garantir o direito à convivência familiar e comunitária. Sobre a adoção internacional, o Plano explicita que esta constitui medida excepcional, a qual deve ocorrer apenas quando esgotados todos os recursos de manutenção em território nacional.

\section{Sobre as diretrizes do Plano Nacional}

Para efetivação do direito de crianças e adolescentes à convivência familiar e comunitária, o Plano Nacional estabelece as seguintes diretrizes: centralidade da família nas políticas públicas; primazia da responsabilidade do Estado no fomento de políticas integradas de apoio 
A convivência familiar e comunitária é direito da criança e do adolescente...

à família; reconhecimento das competências da família na sua organização interna e na superação de suas dificuldades; respeito à diversidade étnico-cultural, à identidade e orientação sexuais, à equidade de gênero e às particularidades das condiçôes físicas, sensoriais e mentais; fortalecimento da autonomia do adolescente e do jovem adulto na elaboração do seu projeto de vida; garantia dos princípios de excepcionalidade e provisoriedade nos programas de famílias acolhedoras e de acolhimento institucional de crianças e de adolescentes; reordenamento dos programas de acolhimento institucional; adoção centrada no interesse da criança e do adolescente; controle social das políticas públicas.

O plano de ação faz referências também às questôes da avaliação e do monitoramento de resultados, à previsão orçamentária nas diversas esferas de governo - nacional, estadual e municipal, e organiza as ações planejadas em nove anos, a contar de 2007 até 2015, classificando-as em açôes de curto, médio e longo prazos, além de açóes permanentes.

Muito recentemente (19 de junho de 2009), em assembleia conjunta, o Conselho Nacional de Assistência Social e o Conselho Nacional dos Direitos da Criança e do Adolescente aprovaram documento ${ }^{4}$ que tem como finalidade regulamentar, no território brasileiro, a organização e oferta de serviços de acolhimento para crianças e adolescentes, no âmbito da política de assistência social.

Reflexôes sobre a responsabilidade da educação frente ao direito da criança e do adolescente à convivência familiar e comunitária

O Plano Nacional de Proteção, Defesa e Garantia do Direito da Criança e do Adolescente à Convivência Familiar e Comunitária é mais um importante passo dado na direção da garantia dos direitos infantojuvenis no Brasil, do ponto de vista de legislação e de regulamentação. Entretanto, é também necessário considerar que compete aos operadores do Direito, aos profissionais, aos gestores que atuam na formulação e execução das políticas públicas e toda a sociedade, envidarem os esforços para que esses documentos legais se transformem em práticas cotidianas. Por si só esse plano não modifica a realidade das crianças e adolescentes brasileiros. É imprescindível muito esforço e articulação das políticas públicas. Ainda que estejam sempre presentes na grande maioria dos discursos, na voz de políticos ou dos técnicos do 
poder público, as vaidades pessoais e as disputas pelos micropoderes boicotam esses movimentos de forma categórica.

O entendimento do plano passa pela atualização do conceito da instituição "família", reconhecendo sua dinâmica, a diversidade da organização familiar, as possibilidades de novos arranjos, a complexidade e riqueza de vínculos, superando o modelo tradicional que, na prática, há muito se esgarçou. Desloca o foco da importância da estrutura familiar para as funçōes familiares de cuidados e socialização, estimula a responsabilização da figura paterna para uma ação mais efetiva, com maior envolvimento, proximidade e intimidade.

$\mathrm{Na}$ elaboração de programas e projetos das políticas públicas, é conveniente priorizar a promoção de trabalhos com a centralidade na família, partindo da abordagem que inicie a intervenção com um exame cuidadoso sobre o que ela possui, identificando suas potencialidades. Mediante esse potencial, promover açôes que sejam libertadoras, que estimulem emancipação, que considere e conte com a rede social de apoio, revelando também a necessidade da profunda articulação das diversas áreas: desenvolvimento social, urbano e econômico, as demandas de habitação, de trabalho e renda, de saneamento, de segurança alimentar, da saúde (mental, emocional e física), do esporte e lazer, da cultura e da educação.

Articular as açôes das políticas sociais e dos demais operadores do sistema de garantia de direitos com a sociedade civil organizada é uma forma de superar os obstáculos, de promover o reordenamento dos programas de acolhimento, visando cumprir seu caráter de excepcionalidade e provisoriedade, o investimento na reintegração à família, a preservação do vínculo entre grupo de irmãos, a permanente comunicação com a Justiça da infância e a articulação com a rede de serviços.

A qualificação é prioridade para todos aqueles que estejam envolvidos de forma direta ou indireta nos programas de atendimento. É fundamental o investimento na formação e no apoio aos educadores e/ ou cuidadores para manter os níveis de qualidade e adequação nesse atendimento, desempenho profissional especializado, tratamento personalizado e adoção de estratégias metodológicas condizentes com as necessidades físicas, psicológicas e sociais da criança, do adolescente e de sua família. Isso inclui desde a garantia de espaços privados, objetos de uso pessoal, registros, escuta ativa, direito a ter sua opinião 
A convivência familiar e comunitária é direito da criança e do adolescente...

considerada, até a escolha das atividades em que a criança será inserida, entre outras decisões. É interessante também que esses profissionais saibam lidar com questóes que envolvam saúde sexual e reprodutiva, prevenção ao uso do álcool e outras drogas.

A qualidade da formação da equipe técnica é determinante para a construção de projetos coletivos, solidários, compartilhados desde a sua concepção com os beneficiários e apoiados pelos poderes constituídos no início, mas que deverão tornar-se autossustentáveis.

Sobre a dimensão que envolve a formação da equipe de atendimento, há que considerar o trabalho de intervenção junto a essas famílias para que elas compreendam os motivos que levaram ao abrigamento da criança, a importância da convivência familiar, as responsabilidades e os papéis advindos da paternidade/maternidade, maneiras para relacionamentos saudáveis; os cuidados com a criança para o desenvolvimento integral; a forma de descobrir as potencialidades próprias que existem nessa família e superar a situação difícil; a adoção de novos comportamentos dentro da família que respeitem e valorizem os direitos das crianças, adolescentes, idosos, portadores de necessidades especiais; fortalecimento da autonomia (do ponto de vista econômico, social, emocional) e o direito ao acesso a bens e serviços públicos, fazendo com que o conjunto de ações possa levar à reintegração familiar, cumprindo assim o objetivo pré-estabelecido.

No rol de capacitação, é preciso incluir também um programa que vise preparar as famílias selecionadas para o acolhimento de crianças e adolescentes no formato de "família acolhedora-solidária-guardiā" (já citada anteriormente). Deverá abordar os aspectos referentes à operacionalização jurídico-administrativa do programa, etapas do desenvolvimento da criança e particularidades da faixa etária, direitos da criança ou adolescente, novas configuraçôes familiares, forma de lidar com fragilidades e conflitos, estabelecimento de limites, resgate da autoestima, a escuta ativa, enfim, o papel das famílias que acolhem essa criança ou adolescente, em caráter de provisoriedade, e poderá, inclusive, ser fator decisivo no fortalecimento da família de origem e na reintegração da criança.

Em decorrência das considerações anteriores, entendemos ser indispensável repensar as políticas de recursos humanos que envolvem desde a definição de perfil profissional no ato de recrutamento, seleção 
e contratação, passando pelas ações de desenvolvimento/formação, incluindo a política de carreira, salários e benefícios, uma vez que estes profissionais terão papel fundamental na implementação do Plano e que sua própria condição de saúde física, social, emocional e espiritual será determinante na atuação profissional junto às famílias. São indispensáveis os sistemas de acompanhamento, monitoramento, avaliação dos programas e processos que exigem desenvolvimento de metodologias de trabalho. Esses processos serão mais bem conduzidos se exercidos por lideranças competentes e educadoras, com vocação para o exercício democrático e participativo.

Outra implicação bastante complexa para o caso de abrigamento da criança ou adolescente: o encaminhamento da equipe técnica deverá considerar que ela tem direito a permanecer mais próximo a sua residência, atender melhor às suas peculiaridades, dar continuidade a vida escolar na mesma escola que vinha frequentando e aos equipamentos comunitários aos quais esteja vinculada, sempre no sentido da manutenção dos vínculos. As exceções se concentram, naturalmente, para as crianças que estiverem em situação de risco, exigindo segurança especial.

Muito além da ação professor-aluno em sala de aula, resguardada naturalmente sua relevância, é preciso considerar as mudanças que esse plano carrega em seu pano de fundo. Necessidade de mudanças profundas da maioria das pessoas na interação/relação com a família e na sociedade; na função educadora como mães/pais; naquilo que se propaga na mídia, nos conteúdos circulantes nos jornais, na televisão, na internet e em todo o processo de comunicação.

Nesse sentido, nossa humilde contribuição remete para a importância da reflexão séria, mas, principalmente, para a mudança da concepção que hoje norteia a sociedade na forma de olhar e compreender essa célula chamada família. Destaca-se, no cenário atual, uma prática para proteger crianças e adolescentes que tem se revezado entre o autoritário, o assistencialista e o minimalista. $\mathrm{O}$ que é recorrente na sociedade é a rápida decisão de retirar a criança da situação de pobreza, abandono ou violência para espaços que garantam melhorias físicas, incluindo, por exemplo, cama, cobertor, todas as refeições e, se for possível, que continue frequentando a escola. É bem mais raro que se esteja atento ao que é indispensável a todo ser humano: afeto, confiança, proteção, 
A convivência familiar e comunitária é direito da criança e do adolescente...

segurança, amor, tudo aquilo que efetivamente assegura-lhe autoestima, convivência saudável, equilíbrio e coragem para superar os obstáculos e desafios da vida. Privilegia-se a condição material, em detrimento do emocional, do social e do espiritual.

Da análise mais aprofundada de todas as propostas contempladas nos documentos mencionados, na legislação (CF, ECA, LOAS, SUS, SUAS, LDB, Planos etc.), destacamos o papel fundamental que a educação pode promover. Falamos da educação na concepção ampliada, desde o sistema formal até o informal, que perpassa o universo escolar, mas também de toda ação educativa, de formação específica, de aperfeiçoamento e integração de novos profissionais, sejam os atuantes nas organizações da sociedade civil ou na rede oficial de serviços públicos, em especial os que exercem suas funções na esfera municipal. São os profissionais que efetivam as políticas, que as tornam concretas, através da intervenção cotidiana junto a essas crianças, adolescentes e suas famílias.

Além do que já foi apontado anteriormente, cabe-nos alertar para a extensa responsabilidade atribuída à educação. Aceitando que, sozinha, ela não possa superar todas as mazelas herdadas ao longo do processo histórico e social, tem papel decisivo na revisão de conteúdos das propostas pedagógicas, dos planos de ensino que envolvem formação teórica sólida, mas também das práticas e vivências que se desenrolam nos espaços educacionais; da formação humanizada, reconhecendo todos como titulares de direito e tirando das letras do texto para a vivência cotidiana. A título de exemplo, podemos lembrar aqui a importância das ações de profissionais da educação e da saúde, como agentes facilitadores na identificação, caracterização e denúncia de situações de violação de direitos que se traduzem em surras, abuso sexual, queimaduras, falta de alimentação e de cuidados de higienização e saúde, entre tantas outras negligências e violências.

$\mathrm{Na}$ ação de professores pode-se ainda considerar sua influência nas situações de convivência, envolvendo situaçóes de discriminação, preconceitos, injustiças e humilhaçôes. Isso já sinaliza para a premente necessidade de abordagens do tema em cursos como Direito, Pedagogia, Medicina, Enfermagem, Fisioterapia, Terapia Ocupacional, Nutrição, Odontologia e as interfaces com profissionais oriundos de outras graduações como Administração, Publicidade, Propaganda, Marketing 
e Jornalismo. Talvez não se possa deixar nenhuma formação fora desta lista. Todas, direta ou indiretamente, exercem influência sobre todo o contexto, seja no âmbito público ou privado, seja no trabalho, na educação familiar, na comunidade.

E por que não incluir também a formação anterior a esta, desde sua fase inicial de socialização, no aprendizado sobre ética, valores, convivência/relacionamento que perpassam todas as fases da criança e do adolescente na escola, da educação infantil ao ensino médio, técnico ou profissionalizante.

De alguma forma, implica também em como preparar os pais e mães para lidar com a formação dos filhos, na participação junto à escola, na comunidade e no bairro, refletindo seus resultados na própria sociedade. É no seio da família que também se formam todos os profissionais - professor(a), enfermeiro(a), médico(a), advogado(a), juiz(a), economista, publicitário(a), empresário(a), bibliotecário(a), recepcionista, dentista, jornalista e outras tantas profissões - e é na sociedade que eles interagem, provocando as transformaçôes desejadas. $\mathrm{Na}$ página 58 do Plano encontra-se o que buscamos retratar nestas últimas consideraçôes e que vem assim explicitado:

Um Plano Nacional de Promoção, Proteção e Defesa do Direito de Crianças e Adolescentes à Convivência Familiar só será integralmente implementado num Estado efetivamente voltado ao bem comum, por governos seriamente comprometidos com o desenvolvimento de políticas públicas de promoção da equidade social e por uma sociedade que tenha, definitivamente, compreendido que a desigualdade social não é prejudicial apenas à população mais pobre, aos excluídos e "deslocados" da nossa ordem social, mas que ela atinge e prejudica a sociedade como um todo e a cada um; que ela é a violência maior onde se nutrem todas as demais violências.

Finalizando, destacamos aqui a responsabilidade coletiva e individual na realização de ações que concretizem os planos discutidos ao longo de décadas, para transformar a sociedade, com vistas à justiça, à equidade social e, fundamentalmente, ao cumprimento da tão sonhada "doutrina da proteção integral" que o ECA preconizou para todas as crianças e adolescentes.

Daqueles a quem compete definir ou aprovar os orçamentos públicos e executar as ações previstas são esperadas mais do que boas 
A convivência familiar e comunitária é direito da criança e do adolescente...

intenções ou discursos. Esperamos que todas as medidas sejam tratadas com responsabilidade, seriedade, transparência, agilidade e sabedoria.

Recebido em abril de 2010 e aprovado em agosto de 2010

\section{Notas}

1. Convenção sobre os Direitos da Criança, ratificada pelo Brasil em 24 de setembro de 1990.

2. Fonte: Plano Nacional de Proteção, Defesa e Garantia de Direito da Criança e do Adolescente à Convivência Familiar e Comunitária (p. 74).

3. Cf. Plano Nacional de Proteção, Defesa e Garantia do Direito da Criança e do Adolescente à Convivência Familiar e Comunitária (p. 17 a 19).

4. Para saber mais sobre esse documento, ver Orientações Técnicas: Serviços de Acolhimento para Crianças e Adolescentes (jun. 2009). Disponível em: <www.presidencia.gov.br/ estrutura_presidencia/sedh>

\section{Referências}

BRASIL. Constituição (1988). Constituição da República Federativa do Brasil. Disponível em: <http:/www.planalto.gov.br/ccivil_03/constituição/constitui\%C3\%A7ao.htm>. Acesso em: 12 fev. 2010.

BRASIL. Lei n. 8.069, de 13 de julho de 1990. Dispõe sobre o Estatuto da Criança e do Adolescente e dá outras providências. Diário Oficial da União, Brasília, DF, 16 jul 1990. Disponível em: <http:/ www.planalto.gov.br/ccivil_03/LEIS/L8069.htm>. Acesso em: 12 fev. 2010 .

BRASIL. Lei n. 9.394, de 20 de dezembro de 1996. Estabelece as diretrizes e bases da educação. Diário Oficial da União, Brasília, DF, 23 dez. 1996. Disponível em: <portal.mec.gov.br/arquivos/pdf/ldb.pdf>. Acesso em: 12 fev.2010

BRASIL. Presidência da República. Secretaria Especial dos Direitos Humanos. Conselho Nacional dos Direitos da Criança e do Adolescente. Plano Nacional de Promoção, Proteção e Defesa do Direito de Crianças e Adolescentes à Convivência Familiar e Comunitária. Brasília, DF: CONANDA, 2006. Disponível em: <www.presidencia.gov.br/estrutura_presidencia/ sedh/..../pncfc.pdf>. Acesso em: 12 fev. 2010. 
COSTA, A.C.G. Um histórico do atendimento sócio-educativo aos adolescentes autores de ato infracional no Brasil: mediação entre o conceitual e o operacional. In: BRASIL. Ministério da Justiça. Secretaria Nacional de Direitos Humanos. Políticas públicas e estratégias de atendimento sócio-educativo ao adolescente em conflito com a lei. Brasília, DF, 1998.

RIZZINI, I. A criança e a lei no Brasil. Brasília, DF: UNICEF/CESPI/Usu, 2000.

SILVA PEREIRA, T. Direito da criança e do adolescente: uma proposta interdisciplinar. Rio de Janeiro: Renovar, 1996.

TERRA DOS HOMENS. Do abrigo à família. Rio de Janeiro: ABTH, 2002. Disponível em: <www.terradoshomens.org.br> 